Article

\title{
Quality of Work Life (QoWL) and Perceived Workplace Commitment among Seasonal Farmers in Nigeria
}

\author{
Haruna M. Moda ${ }^{1, *(\mathbb{D}, \text { Christopher Nwadike }}{ }^{2}$, Mela Danjin ${ }^{3}$, Francis Fatoye ${ }^{1}$, Chidozie E. Mbada ${ }^{4}$, \\ Louise Smail ${ }^{1}$ and Pauline J. S. Doka ${ }^{3}$ \\ 1 Department of Health Professions, Manchester Metropolitan University, Manchester M15 6GX, UK; \\ f.fatoye@mmu.ac.uk (F.F.); L.smail@mmu.ac.uk (L.S.) \\ 2 Department of Agricultural Technology, Forestry College of Forestry, Jos 930253, Nigeria; \\ chrisnwadike@fffjos.edu.ng \\ 3 Department of Public Health, College of Nursing and Midwifery, Gombe State 760251, Nigeria; \\ danjin67@yahoo.com (M.D.); paulinedoka@gmail.com (P.J.S.D.) \\ 4 Department of Medical Rehabilitation, College of Health Sciences, Obafemi Awolowo University, \\ Ile-Ife 220005, Nigeria; doziembada@yahoo.com \\ * Correspondence: h.moda@mmu.ac.uk
}

check for updates

Citation: Moda, H.M.; Nwadike, C.; Danjin, M.; Fatoye, F.; Mbada, C.E.; Smail, L.; Doka, P.J.S. Quality of Work Life (QoWL) and Perceived Workplace Commitment among Seasonal Farmers in Nigeria. Agriculture 2021, 11, 103. https:// doi.org/10.3390/agriculture11020103

Academic Editor: Sanzidur Rahman Received: 21 December 2020

Accepted: 22 January 2021

Published: 26 January 2021

Publisher's Note: MDPI stays neutral with regard to jurisdictional claims in published maps and institutional affiliations.

Copyright: (c) 2021 by the authors. Licensee MDPI, Basel, Switzerland. This article is an open access article distributed under the terms and conditions of the Creative Commons Attribution (CC BY) license (https:// creativecommons.org/licenses/by/ $4.0 /)$.

\begin{abstract}
This study set out to research the impact of Quality of Work Life (QoWL) in Low- and Middle-Income Countries (LMICs) and the perception of farm workers regarding how both intrinsic and extrinsic control elements within and outside the work setting impact their productivity within the farming industry in Nigeria. To our knowledge, this is the first study that has considered QoWL among farm workers in Nigeria. Farm workers in the Middle Belt region in Nigeria $(n=435)$ were surveyed using a QoWL questionnaire consisting of 32 Likert scale items to measure their perceived quality of work life based on seven dimensional factors. Results indicated that more than half $(60.6 \%)$ of the sampled group confirmed working far above the national working hours of $40 \mathrm{~h}$ per week. Significant differences exist between respondent gender on control at work (CAW) $(F=10.03$, $p<0.001)$ and working conditions (WCS) $(F=12.04, p<0.001)$, with women having better QoWL. Farm worker job satisfaction, especially in LMICs, is an important element that can lead to high productivity and sustainability of the sector. To achieve a level of sustainability and food security in Nigeria, there is the need to improve opportunities for greater stability among farmers. Farm workers could benefit from tailored training initiatives around stress management and work-life balance, as well as workplace safety nad health and wellbeing as a means of boosting their confidence and enhance sustainable productivity. In addition, this paper holds the potential to inform framework development for assessing QoWL within the farming industry in Nigeria and encourage further research around the impact of job insecurity on the nation's food security.
\end{abstract}

Keywords: quality of work life; stress; wellbeing; productivity; social sustainability; LMICs

\section{Introduction}

The American Automobile Industry Association was the first body that considered Quality of Work Life (QoWL) among its members and called for more attention towards employee welfare and health over financial turnover [1]. QoWL denotes employees' experience of their working environment, which involves employees' perception of their physical and psychological well-being obtained from their work [2]. In a broad sense, when assessing employee QoWL, areas that include interpersonal relationships, workplace management, and the work-family dynamic should be considered. In the western world, several studies have examined QoWL among farmers, and concluded that more focus should be directed towards their welfare and work-life balance, as they form an important component of a nation's labor force [2-4].

The agricultural sector plays an important role toward the enhancement of a nation's economy. In addition, the zero-hunger fight and promotion of economic growth as part 
of sustainable development goals have seen the rise in agricultural enterprise, especially in low- and middle-income countries (LMICs). However, most agricultural activities in LMICs are manually driven and have health and safety challenges $[4,5]$. Nigeria, like other LMICs, considers agriculture as a major contributor to its economy, with more than half of the active population engaged in different forms of agricultural practices. Olowogbon et al. [4] stated that $80 \%$ of the Nigerian population are smallholder farmers.

Despite the prominent role of agriculture in poverty reduction in Nigeria, agricultural practices are still hazardous, thereby exposing farm workers to several work-related risks, including agricultural stressors [5,6]. To address these challenges, the Food and Agricultural Organization (FAO) sustainability assessment of the Food and Agriculture Systems (SAFA) guidelines [7] has placed emphasis on four dimensions to achieve sustainability, including good governance, environmental integrity, economic resilience and social well-being, where the social sustainability approach encourages the promotion of a decent livelihood, labor rights and safety, among other set values. Considering the amount of time farmers spend working outside (in most cases, in unfavorable weather conditions), it is paramount that these employees have a certain degree of satisfaction around their quality of life at work as it relates to their physical, psychological and spiritual well-being [8,9]. In addition to this, work-related stress is widespread among farm workers, and it has a significant impact on their QoWL.

Several factors have been identified as adding to the stress experienced among farmers and other workers in the agricultural sector. These include personal hazards, time pressures, job insecurity, poor work conditions, absence of control over work demand, lack of support and poor work-life balance [10-14]. On this note, Elkington [15] opined that it might prove hard for a community to address environmental, economic and social sustainability without taking into account the tight relationship between them. As such, there is a need to consider the role of QoWL as an indicator for long term sustainability within the system.

In addition, there is no doubt that the COVID-19 pandemic will have an impact on the QoWL of agricultural workers by heightening the already unsatisfactory working conditions, as well as negatively affecting worker productivity [16]. To improve employee engagement and the delivery of better performance, there is a need for an approach that allows measurement of both extrinsic and intrinsic factors, such as employee engagement, satisfaction and commitment level, to enable the organization to compete favorably with any of its competitors $[17,18]$. Most often, efforts to conceptualize and measure a "healthy workplace" have placed more emphasis on work-related injuries, accidents and illness. However, a balance that offers the necessary internal relations conducive to good health and well-being among these employees are areas that require further strengthening $[19,20]$.

Although several authors have made an effort to define QoWL, in sum, it is the total quality of an employee's work life within an organization. QoWL impacts the way that an employee responds to their establishment, their job satisfaction, job involvement, performance, absenteeism rate and employee turnover $[14,17,21,22]$. In addition, QoWL affects both job satisfaction and satisfaction derived from other life domains, including the family, leisure, social and economic aspects of an individual. QoWL should be considered as a process by which an organization reacts to their employee requirements, aimed at offering them a chance to take part in decisions that are likely to impact on their lives at work [23]. Hence, factors that contribute to the improvement of QoWL should be considered to ensure that employees are guaranteed good work experiences with bosses and/or subordinates [24,25].

As earlier identified, low QoWL among employees can lead to a high rate of absenteeism, early retirement and poor professional conduct, among others, which can affect an individual's health and relationships [22,26]. Above all, successful organizations have invested in their human capital and in the creation of a workplace climate that guarantees job satisfaction, with tangible results evident among their employees' quality of life. This approach enhances the successful maintenance of a steady supply level of employment within the agriculture sector to guarantee sustainable food security. 
The aim of this paper is to expand on the research around the impact of QoWL in LMICs and farm workers perceptions on how both intrinsic and extrinsic control elements within and outside the work setting impact on their productivity within the farming industry in Nigeria while advancing measures to help strengthen the social dimension towards sustainability within the sector.

\section{Materials and Methods}

\subsection{Respondents}

Farm workers drawn from private and government farms located in the Middle Belt region of Nigeria (which is comprised of the Benue, Kaduna and Plateau states) took part in this study. The recruitment period was 40 days, within which a sample of 435 consenting farmers volunteered to take part in the study and provided their answers to the questions asked. Quality of working life questionnaires [27] were distributed via an online survey platform (Online Survey, JISC, Bristol, UK). Inclusion criteria were: employees of private and public-owned farms, individuals whose main source of income is through farm work, over the age of 18 and able to communicate in English. All subjects gave their informed consent for inclusion before they participated in the study. The study was conducted in accordance with the Declaration of Helsinki, and the protocol was approved by the Department of Agricultural Technology, Forestry Research Institute of Nigeria. Jos, Ethics Committee.

\subsection{Instrumentation}

The QoWL questionnaire (Table S1) consisted of 32 Likert scale items (from totally disagree $=1$ to totally agree $=5$ ) that sought to measure farm workers' perceived quality of life based on seven dimensional factors: controls at work (CAW); general well-being (GWB); home-work interface (HWI); job / career satisfaction (JSC); stress at work (SAW); working conditions (WCS) and employee engagement (EEN) [27]. Other background information included in the questionnaire included: age, gender, typical work hours per week, emolument mode of payment and number of days off work due to ill health and caring responsibilities.

\subsection{Data Analysis}

Data analysis was undertaken using the SPSS 23.0 software package for Windows. Raw data were inspected and cleaned to remove cases with empty or a greater percentage of missing items/responses. Cronbach's alpha coefficient was used to assess the internal reliability of the set of items based on the seven domains: CAW, EEN, GWB, HWI, JCS, SAW, WCS and summaries of overall QoWL, expressed as a number between 0 and 1 [28]. The QoWL continuous variables were reported as mean \pm standard deviation, while categorical variables were presented as frequencies and percentages. A one-way ANOVA was conducted to identify whether age, gender, work pattern etc. had an effect across the seven QoWL dimensions measured, in addition to scores among groups based on socio-demographic factors and QoWL domains and summaries. Statistical significance was set at $p<0.05$.

\section{Results}

\subsection{Reliability Test}

Table 1 shows that a Cronbach's alpha of $>0.70$ was considered satisfactory. Reliability testing using Cronbach's alpha has been used to measure the internal consistency of variables. The Cronbach's alpha value for the 32 items in the structured questionnaire was measured at 0.892 (Table 1). Factor one (CAW) was comprised of three items and relates to the level of control employees feel they have over workplace decisions; this factor has a subscale reliability of 0.751 . In addition, factor three (HWI) relates to family and work-life balance and retuned a sub-scale reliability of 0.737 . Four items were applied to measure the 
extent to which employees' perceptions around exposure to workplace pressure or stress from daily work activities (SAW) and returned a sub-scale reliability of 0.703 .

Table 1. Overall Cronbach's alpha and 32-item, seven-factor component sub-scale for the farm workers data set. SD: standard deviation; QoWL: Quality of Working Life.

\begin{tabular}{cccc}
\hline Dimensional Factor Domains & Cronbach's Alpha & No. of Items & Mean \pm SD \\
\hline Controls at work (CAW) & 0.751 & 3 & $3.21 \pm 1.0$ \\
Employee engagements (EEN) & 0.716 & 3 & $3.37 \pm 0.6$ \\
General wellbeing (GWB) & 0.756 & 5 & $3.28 \pm 0.7$ \\
Home-work = interface (HWI) & 0.737 & 3 & $3.25 \pm 0.9$ \\
Job/career satisfaction (JCS) & 0.784 & 5 & $3.27 \pm 0.8$ \\
Stress at work (SAW) & 0.703 & 4 & $3.33 \pm 0.6$ \\
Working conditions (WCS) & 0.705 & 32 & $2.99 \pm 0.8$ \\
Overall QoWL & 0.892 & $3.24 \pm 0.6$ \\
\hline
\end{tabular}

\subsection{Demographic and Background Variables}

Table 2 depicts farm workers' demographics and work-related characteristics. Overall, the survey response rate of $43.6 \%$ was highly related to the interests of the respondent, survey collection time, length of survey, and assurance of privacy and confidentiality. A total of 436 respondent responded to the online survey, of which $47.6 \%$ were male and $48.5 \%$ were female; $55.4 \%$ were within the age band of $25-44$ years. More than half $(60.6 \%)$ of the sampled group confirmed working far above the national working hours of $40 \mathrm{~h}$ per week, as specified under the National Minimum Wage Act, and only $16.3 \%$ said they do not have any form of caring responsibilities (Table 2). About half (51.2\%) of the respondents received a monthly salary and $15.2 \%$ of them worked despite having a disability.

Table 2. Socio-demographics and job characteristics of respondents.

\begin{tabular}{lll}
\hline Variable/Category & $\boldsymbol{n}(\%)$ & Mean \pm SD \\
\hline Age & $23(5.3)$ & \\
$18-25$ & $240(55.3)$ & $1.55 \pm 0.57$ \\
$25-44$ & $142(32.7)$ & \\
$45-59$ & $29(6.7)$ & \\
$>60$ & $211(48.5)$ & $2.41 \pm 0.69$ \\
Gender & $208(47.7)$ & \\
Female & $17(3.9)$ & \\
Male & & \\
Preferred not to say & $66(15.2)$ & \\
Do you have a disability? & $367(84.8)$ & \\
Yes & $39(9.0)$ & \\
No & $132(30.4)$ & \\
Approximately how many hours do you work in a typical week? & \\
$<20$ & $103(23.7)$ & \\
$20-40$ & $105(24.2)$ & \\
41-50 & $55(12.7)$ & \\
$51-60$ & $67(15.4)$ & \\
$>60$ & $166(38.2)$ & \\
Approximate no. of days off work due to ill health in the last year? & \\
None & $112(25.7)$ & \\
1-5 days & $55(12.6)$ & \\
6-10 days & $35(8.0)$ & \\
11-15 days & & \\
>15 days & $222(51.2)$ & \\
How are you paid? & $98(22.6)$ & \\
Salaried (month end) & $114(26.3)$ & \\
Hourly & $71(16.3)$ & \\
Other & $168(38.5)$ & \\
Caring responsibilities & $160(36.7)$ & \\
No & $216(49.5)$ & \\
Young children & & \\
School age children & & \\
Elderly relatives (i.e., parents) & & \\
\hline
\end{tabular}




\subsection{Comparison between Respondents' Quality of Work Life Using Gender and Age Variables}

There was a significant difference between respondent gender for CAW $(F=10.03$, $p<0.001)$ and WCS $(F=12.04, p<0.001)$, whereas six dimensions were found to have statistically significant differences with age: CAW $(F=9.03, p<0.001)$, GWB $(F=12.39$, $p<0.001)$, HWI $(F=11.39, p<0.001)$, JCS $(F=14.15, p<0.001)$, SAW $(F=5.38, p<0.001)$, WCS $(F=10.89, p<0.001)$ and QoWL $(F=15.54, p<0.001)$. This indicates an impact of the job nature on the QoWL among the workers. However, the result of the impact of a disability on the quality of life measure returned insignificant differences across the six dimensions measured, with the exception of CAW $(F=5.13, p=0.024)$. Two questions were asked to measure the stress at work (SAW) domain, and $51.4 \%$ of respondents affirmed to feeling pressured at work, while $43.6 \%$ reported being stressed. Overall, women were found to have a better quality of life across the six domains examined with the exception of employee engagements (EEN) compared to their male counterparts. In addition, respondents within the age group 25-44 showed better QoWL over any other age group (Table 3).

\subsection{QoWL Sub-Scales according to the Job Characteristics of Respondents}

Table 4 presents the one-way ANOVA analysis of job characteristics and their associated factors that were found to have an influence on QoWL among the respondents. The results show that hours of work per week had a significant difference with CAW $(F=18.08, p<0.001)$, GWB $(F=11.77, p<0.001)$, HWI $(F=18.77, p<0.001)$, JCS $(F=13.39$, $p<0.001)$, SAW $(\mathrm{F}=3.29, p<0.05)$ and WCS $(F=5.29, p<0.001)$. There was significant difference between farmers' work hours and their overall QoWL $(F=22.71, p<0.001)$. All but EEN $(F=0.30, p=0.585$ ) were significantly different with jobs requiring repeated lifting. Outcomes based on the comparison between farm work tasks requiring repetitive lifting or forceful hand movements with the seven QoWL dimensions revealed a highly significant difference with CAW $(F=117.53, p<0.001)$, GWB $(F=127.23, p<0.001)$, HWI $(F=93.88$, $p<0.001)$, JCS $(F=122.90, p<0.001)$, SAW $(F=24.66, p<0.001)$ and WCS $(F=135.33$, $p<0.001)$, while EEN $(F=3.61, p=0.058)$ showed no significant difference. A higher level of QoWL was found among respondents that reported working 25-40 h per week, and workers who reported that they are paid monthly have a higher QoWL compared to those paid weekly or daily (Table 4). 
Table 3. Comparison of QoWL sub-scales according to the gender and age of respondents.

\begin{tabular}{|c|c|c|c|c|c|c|c|c|c|c|c|c|c|c|c|c|}
\hline \multirow{2}{*}{ Variables/Categories } & \multicolumn{2}{|r|}{ CAW } & \multicolumn{2}{|r|}{ EEN } & \multicolumn{2}{|r|}{ GWB } & \multicolumn{2}{|r|}{ HWI } & \multicolumn{2}{|r|}{ JCS } & \multicolumn{2}{|r|}{ SAW } & \multicolumn{2}{|r|}{ WCS } & \multicolumn{2}{|r|}{ QoWL } \\
\hline & $\mathbf{N}$ & Mean \pm SD & $\mathbf{N}$ & Mean \pm SD & $\mathbf{N}$ & Mean \pm SD & $\mathbf{N}$ & Mean \pm SD & $\mathbf{N}$ & Mean \pm SD & $\mathbf{N}$ & Mean \pm SD & $\mathbf{N}$ & Mean \pm SD & $\mathbf{N}$ & Mean \pm SD \\
\hline \multicolumn{17}{|l|}{ Gender } \\
\hline Male & 209 & $3.02 \pm 0.9$ & 211 & $3.40 \pm 0.6$ & 208 & $3.18 \pm 0.8$ & 211 & $3.15 \pm 0.9$ & 206 & $3.17 \pm 0.8$ & 208 & $3.32 \pm 0.6$ & 209 & $2.80 \pm 0.8$ & 198 & $3.14 \pm 0.5$ \\
\hline Prefer not to say & 17 & $3.12 \pm 0.7$ & 17 & $3.22 \pm 0.6$ & 16 & $3.21 \pm 0.6$ & 17 & $2.98 \pm 0.6$ & 17 & $3.02 \pm 0.5$ & 16 & $3.25 \pm 0.6$ & 16 & $2.94 \pm 0.6$ & 15 & $3.11 \pm 0.4$ \\
\hline$F$-test & & $10.03 * *$ & & 0.99 & & $3.55^{*}$ & & $4.32 *$ & & $4.47^{*}$ & & 0.23 & & $12.04 * *$ & & $6.77^{* *}$ \\
\hline \multicolumn{17}{|l|}{ Age group } \\
\hline$<25$ & 23 & $3.00 \pm 0.8$ & 23 & $3.33 \pm 0.6$ & 22 & $2.94 \pm 1.0$ & 23 & $2.77 \pm 0.8$ & 23 & $2.73 \pm 1.0$ & 23 & $3.05 \pm 0.8$ & 23 & $2.74 \pm 0.7$ & 22 & $2.94 \pm 0.6$ \\
\hline $25-44$ & 239 & $3.42 \pm 0.9$ & 240 & $3.41 \pm 0.6$ & 239 & $3.46 \pm 0.7$ & 238 & $3.46 \pm 0.8$ & 237 & $3.47 \pm 0.8$ & 235 & $3.41 \pm 0.6$ & 238 & $3.18 \pm 0.9$ & 228 & $3.40 \pm 0.6$ \\
\hline$>60$ & 29 & $3.13 \pm 0.9$ & 29 & $3.20 \pm 0.8$ & 29 & $3.16 \pm 0.5$ & 28 & $3.08 \pm 0.9$ & 28 & $3.18 \pm 0.6$ & 29 & $3.47 \pm 0.7$ & 29 & $2.97 \pm 0.7$ & 27 & $3.15 \pm 0.5$ \\
\hline$F$-test & & $9.03 * *$ & & 1.33 & & $12.39 * *$ & & $11.39 * *$ & & $14.15^{* *}$ & & $5.38^{* *}$ & & $10.89 * *$ & & $15.54^{* *}$ \\
\hline \multicolumn{17}{|c|}{ Do you have a disability? } \\
\hline Yes & 66 & $2.97 \pm 0.9$ & 66 & $3.33 \pm 0.7$ & 65 & $3.14 \pm 0.8$ & 65 & $3.19 \pm 0.9$ & 64 & $3.20 \pm 0.8$ & 64 & $3.38 \pm 0.8$ & 65 & $2.82 \pm 0.7$ & 60 & $3.11 \pm 0.5$ \\
\hline No & 365 & $3.26 \pm 1.0$ & 367 & $3.37 \pm 0.6$ & 362 & $3.30 \pm 0.7$ & 365 & $3.25 \pm 0.9$ & 361 & $3.28 \pm 0.8$ & 363 & $3.32 \pm 0.6$ & 364 & $3.02 \pm 0.9$ & 348 & $3.26 \pm 0.5$ \\
\hline$F$-test & & $5.13 *$ & & 0.29 & & 2.71 & & 0.28 & & 0.54 & & 0.43 & & 3.24 & & 3.10 \\
\hline
\end{tabular}


Table 4. Comparison of QoWL sub-scales according to the job characteristics of respondents.

\begin{tabular}{|c|c|c|c|c|c|c|c|c|c|c|c|c|c|c|c|c|}
\hline \multirow{2}{*}{ Variables/Categories } & \multicolumn{2}{|r|}{ CAW } & \multicolumn{2}{|r|}{ EEN } & \multicolumn{2}{|r|}{ GWB } & \multicolumn{2}{|r|}{ HWI } & \multicolumn{2}{|r|}{ JCS } & \multicolumn{2}{|r|}{ SAW } & \multicolumn{2}{|r|}{ WCS } & \multicolumn{2}{|r|}{ QoWL } \\
\hline & $\mathbf{N}$ & Mean \pm SD & $\mathbf{N}$ & Mean \pm SD & $\mathbf{N}$ & Mean \pm SD & $\mathbf{N}$ & Mean \pm SD & $\mathbf{N}$ & Mean \pm SD & $\mathbf{N}$ & Mean \pm SD & $\mathbf{N}$ & Mean \pm SD & $\mathbf{N}$ & Mean \pm SD \\
\hline \multicolumn{17}{|c|}{ Approximate hours of work/week } \\
\hline$<20$ & 39 & $3.23 \pm 0.8$ & 39 & $3.32 \pm 0.7$ & 39 & $3.30 \pm 0.9$ & 39 & $3.11 \pm 1.03$ & 39 & $3.42 \pm 0.9$ & 39 & $3.39 \pm 0.7$ & 39 & $3.01 \pm 0.8$ & 39 & $3.25 \pm 0.7$ \\
\hline $25-40$ & 132 & $3.70 \pm 0.9$ & 132 & $3.36 \pm 0.6$ & 131 & $3.58 \pm 0.7$ & 132 & $3.73 \pm 0.7$ & 128 & $3.66 \pm 0.7$ & 130 & $3.36 \pm 0.5$ & 131 & $3.53 \pm 0.8$ & 124 & $3.57 \pm 0.5$ \\
\hline $41-50$ & 101 & $3.17 \pm 0.8$ & 103 & $3.43 \pm 0.6$ & 99 & $3.30 \pm 0.7$ & 101 & $3.19 \pm 0.8$ & 99 & $3.34 \pm 0.6$ & 99 & $3.47 \pm 0.6$ & 101 & $2.86 \pm 0.7$ & 89 & $3.25 \pm 0.4$ \\
\hline $51-60$ & 105 & $2.74 \pm 0.9$ & 105 & $3.36 \pm 0.6$ & 104 & $2.96 \pm 0.7$ & 104 & $2.92 \pm 0.9$ & 104 & $2.83 \pm 0.8$ & 105 & $3.20 \pm 0.6$ & 104 & $2.52 \pm 0.7$ & 101 & $2.92 \pm 0.6$ \\
\hline$>60$ & 55 & $3.05 \pm 0.9$ & 55 & $3.33 \pm 0.6$ & 55 & $3.11 \pm 0.7$ & 55 & $2.90 \pm 0.8$ & 55 & $2.95 \pm 0.8$ & 55 & $3.20 \pm 0.6$ & 55 & $2.80 \pm 0.8$ & 55 & $3.05 \pm 0.5$ \\
\hline$F$-test & & $18.08^{* *}$ & & 0.37 & & $11.77^{* *}$ & & $18.77^{* *}$ & & $22.39 * *$ & & $3.29 *$ & & $29.33 * *$ & & $22.71 * *$ \\
\hline \multicolumn{17}{|c|}{ Approximate days off work due to ill health in the last year } \\
\hline $1-5$ days & 165 & $3.39 \pm 1.0$ & 166 & $3.37 \pm 0.5$ & 166 & $3.36 \pm 0.8$ & 166 & $3.40 \pm 0.9$ & 163 & $3.40 \pm 0.9$ & 165 & $3.30 \pm 0.5$ & 166 & $3.19 \pm 1.0$ & 161 & $3.34 \pm 0.7$ \\
\hline $6-10$ days & 112 & $2.95 \pm 0.8$ & 112 & $3.38 \pm 0.7$ & 107 & $3.19 \pm 0.7$ & 110 & $3.13 \pm 0.8$ & 108 & $3.09 \pm 0.7$ & 110 & $3.37 \pm 0.6$ & 112 & $2.75 \pm 0.7$ & 100 & $3.10 \pm 0.5$ \\
\hline 11-15 days & 54 & $3.28 \pm 0.9$ & 55 & $3.53 \pm 0.5$ & 55 & $3.41 \pm 0.7$ & 55 & $3.32 \pm 0.8$ & 54 & $3.28 \pm 0.7$ & 55 & $3.44 \pm 0.8$ & 53 & $2.91 \pm 0.7$ & 52 & $3.32 \pm 0.5$ \\
\hline$>15$ days & 35 & $3.48 \pm 0.7$ & 35 & $3.33 \pm 0.7$ & 35 & $3.23 \pm 0.6$ & 34 & $2.99 \pm 0.8$ & 35 & $3.36 \pm 0.6$ & 35 & $3.31 \pm 0.6$ & 35 & $3.04 \pm 0.6$ & 34 & $3.24 \pm 0.4$ \\
\hline$F$-test & & $5.23 * *$ & & 1.68 & & 2.05 & & $2.94 *$ & & $3.05^{*}$ & & 1.07 & & $5.29 * *$ & & $3.87^{*}$ \\
\hline \multicolumn{17}{|l|}{ How are you paid? } \\
\hline Salaried (monthly) & 222 & $3.39 \pm 1.0$ & 222 & $3.39 \pm 0.6$ & 221 & $3.32 \pm 0.8$ & 221 & $3.32 \pm 1.0$ & 217 & $3.34 \pm 0.9$ & 220 & $3.28 \pm 0.5$ & 221 & $3.11 \pm 0.9$ & 212 & $3.31 \pm 0.7$ \\
\hline Hourly & 96 & $2.93 \pm 0.9$ & 98 & $3.33 \pm 0.6$ & 98 & $3.14 \pm 0.7$ & 97 & $3.19 \pm 0.8$ & 96 & $3.20 \pm 0.7$ & 98 & $3.41 \pm 0.7$ & 97 & $2.84 \pm 0.7$ & 93 & $3.15 \pm 0.5$ \\
\hline Daily & 114 & $3.10 \pm 0.8$ & 114 & $3.36 \pm 0.6$ & 109 & $3.28 \pm 0.7$ & 113 & $3.15 \pm 0.8$ & 112 & $3.17 \pm 0.7$ & 110 & $3.33 \pm 0.6$ & 112 & $2.87 \pm 0.7$ & 103 & $3.16 \pm 0.5$ \\
\hline$F$-test & & $9.00 * *$ & & 0.28 & & 2.17 & & 1.65 & & 2.19 & & 1.38 & & $5.042 * *$ & & 3.59 \\
\hline No & 257 & $3.56 \pm 0.8$ & 258 & $3.38 \pm 0.6$ & 253 & $3.53 \pm 0.6$ & 256 & $3.55 \pm 0.8$ & 252 & $3.58 \pm 0.6$ & 254 & $3.45 \pm 0.6$ & 256 & $3.32 \pm 0.7$ & 241 & $3.49 \pm 0.5$ \\
\hline$F$-test & & $108.51 * *$ & & 0.3 & & $94.46^{* *}$ & & $88.52 * *$ & & $140.89^{* *}$ & & $26.16^{* *}$ & & $131.12 * *$ & & $154.29^{* *}$ \\
\hline \multicolumn{17}{|c|}{ Job requires repetitive or forceful hand movements, etc. } \\
\hline Yes & 179 & $2.7 \pm 0.9$ & 181 & $3.30 \pm 0.6$ & 178 & $2.86 \pm 0.7$ & 180 & $2.81 \pm 0.8$ & 176 & $2.83 \pm 0.8$ & 178 & $3.17 \pm 0.6$ & 178 & $' 2.51 \pm 0.7$ & 167 & $2.87 \pm 0.5$ \\
\hline No & 251 & $3.59 \pm 0.8$ & 251 & $3.41 \pm 0.6$ & 248 & $3.58 \pm 0.6$ & 249 & $3.57 \pm 0.8$ & 247 & $3.58 \pm 0.6$ & 248 & $3.45 \pm 0.6$ & 250 & $3.34 \pm 0.7$ & 239 & $3.50 \pm 0.5$ \\
\hline$F$-test & & $3.22 \pm 0.9^{* *}$ & & 3.61 & & $127.23^{* *}$ & & $93.88^{* *}$ & & $122.90^{* *}$ & & $24.66^{* *}$ & & $135.33^{* *}$ & & $159.52 * *$ \\
\hline
\end{tabular}

${ }^{*} p<0.05$ significant, ${ }^{* *} p<0.001$ highly significant. 


\subsection{Mean QoWL Score Comparison among Employees}

The average score for the seven QoWL dimensions evaluated was 3.24, with EEN having the highest mean score while WCS had the lowest mean score. Significant differences were found within the sub-scales used to measure the respondent's work commitment and its associated impact on their personal lives $(p<0.001)$. The results indicated that as employees work longer hours performing strenuous farm work, including lifting and moving objects around, their QoWL tends to decline (Table 5).

Table 5. Mean scores of QoWL sub-scale perception among respondents.

\begin{tabular}{ccccccc}
\hline \multirow{2}{*}{ QoWL Sub-Scales } & F/t-test & df & $\boldsymbol{p}$-Values & Mean Difference & \multicolumn{2}{c}{ 95\% Confidence Interval of the Difference } \\
\cline { 5 - 7 } & & & & & Lower & Upper \\
CAW & 70.221 & 433 & $0.001^{*}$ & 3.21 & 3.1243 & 3.3043 \\
EEN & 115.370 & 435 & $0.001^{*}$ & 3.37 & 3.3111 & 3.4259 \\
GWB & 91.426 & 429 & $0.001^{*}$ & 3.28 & 3.2049 & 3.3458 \\
HWI & 76.932 & 432 & $0.001^{*}$ & 3.25 & 3.1901 & 3.3309 \\
JCS & 85.617 & 426 & $0.001^{*}$ & 3.27 & 3.2723 & 3.3882 \\
SAW & 112.996 & 429 & $0.001^{*}$ & 3.33 & 2.9111 & 3.0692 \\
WCS & 74.336 & 431 & $0.001^{*}$ & 2.99 & 3.1796 & 3.2934 \\
QoWL & 111.836 & 409 & $0.000^{*}$ & 3.24 & & \\
\hline
\end{tabular}

* Significant, $p<0.001$.

\section{Discussion}

To our knowledge this is the first study that has considered QoWL among farm workers in Nigeria and as such, outcomes from this study will help to improve the worklife balance among farmers and promote decent work policy implementation. Enhancing farm workers' well-being is paramount for the promotion of sustainable farming practices and to guarantee food security, especially among farmers in low- and middle-income countries (LMICs). Salary has been acknowledged as a part of the defining factors in the discontent among respondents in the QoWL. From the results, it was evident that more than half $(60.6 \%)$ of the sampled group attest to working above the national working hours of $40 \mathrm{~h}$ per week, as specified under the National Minimum Wage Act, in order to meet their financial target. In addition, $83.7 \%$ affirmed to having care responsibilities towards their children and/or elderly relatives. There is a high rate of job burnout among farm workers, especially for male respondents; female farm workers were found to have a better quality of life compared to their male counterpart. This finding supported the earlier work that women tend to possess stronger emotions and report a higher level of well-being as compared to men [29]. Accordingly, a recent study elucidated that several factors, including working time, financial stability and care responsibilities, significantly influence farm worker job satisfaction and their quality of work life [30]; similar factors were evident among the respondents that took part in our study. Long working hours and the nature of farm work are likely factors that influence the work-life balance among seasonal farmers. Based on this study, this can present an inverse relationship between work and family conflict among the group-where the level of work interference on family life increased, there was a decrease in quality of life. This finding is supported by previous studies where workplace demand, take home pay, work environment and social engagement were found to have a significant impact on self-reported quality of life among respondents [29,31,32]. In addition, Nanjundeswaraswamy and Swamy [23] discussed that personal needs attainment can lead to positive QoWL among employees where an organization rewards employees either in the form of compensation, promotion, recognition or career development that meets their expectations. This outcome was viewed negatively among the participants in their response to "When I have done a good job, it is acknowledged by my line manager", with $52 \%$ considering the reward culture within their establishment as not encouraging. Another factor considered as having an impact on QoWL among the participants is the level of work demand and stress faced, as workers that 
reported working $25-40 \mathrm{~h}$ per week were found to have a higher QoWL compared to those working extra hours. In addition to this, other self-reported factors such as forgetfulness, sleep disturbances, mental fatigue, stress and anxiety were likely to impact farm workers as a result of working longer hours [29,33,34].

Health and safety within the work environment, training provisions and social integration are associated with work-life balance. Based on the assessment of the question "The organization/employer communicates safety issues well with its employees", $69.2 \%$ of the respondents said they do not feel that their health and safety is given necessary attention. Considering farming practices in Nigeria, it is safe to conclude that most farm establishments have inadequate infrastructure in place to support worker well-being, thereby exposing workers to workplace hazards, which is likely to impact on their quality of life. Based on workplace observations during data gathering, almost all workers witnessed on the farm site tended not to have any form of personal protective equipment, and mostly took their break underneath available tree shade on the farm. The outcome of this observation was further corroborated in the working conditions (WCS) domain question, where $59.6 \%$ of the respondents expressed their reservations around their working conditions, while the provision of adequate facilities to enable employees to operate efficiently had a similar response, with $56.4 \%$ expressing their dissatisfaction. In addition, $47.6 \%$ view their health and safety arrangement at work as inadequate and requiring further improvement. Considering that most farm workers in Nigeria are employed either on an hourly, daily or seasonal basis, the provision of adequate welfare facilities and personal protective equipment are things that are frequently not taken seriously among the operators of these farm enterprises. As reported earlier, job security as well as adequate resources to enable employees to perform their job in a safe and efficient manner are factors that can help drive positive QoWL changes among individuals [23].

From our study, it was evident that work-life balance affects the QoWL among the respondents. As shown in the results, $83.7 \%$ of respondents said they have care responsibilities, which indicates that individuals tend to draw from their family time in order to fulfil their job demands, especially as a high number of respondents reported working far above the national working hours. In addition, pressure from work demands and the level of stress among the famers was found to be high among the study population. Also, poor working conditions and the need for repetitive lifting and pushing of heavy objects on the farm has been associated with the development of musculoskeletal disorders, such as lower back pain, joint injuries and repetitive strain injuries. These disorders are common within the farming sector, which could be another factor that has an impact on the QoWL of the employees $[35,36]$. These factors are related to both the intrinsic and extrinsic factors associated with the nature of work undertaken, and its frequency may be outside of the control of each individual, despite the fact that it might influence their state of being. Our findings echo the report by Ramesh and Madhavi [12] where weather, work demand, farm hassles, financial situation, and social interactions were associated with increased stress levels among farm workers, and financial factors play an important role in the stress and wellbeing among their sampled group.

Our study considered associated farm work demand and its impact on workers' personal lives. From our findings, it is clear that a high level of stress is being reported among the sampled group, with a similar number reporting feeling the pressure of the job demands on their personal lives. To add to this, while the role that agriculture plays in safeguarding the food security of a nation, its culture and traditions are evident, and there is a need to ensure social sustainability within the sector to guarantee farm workers safety and well-being, as the outcomes from this study reveal a gap that exists around this subject. Aside from the impact of climate change, farm workers that took part in the study were faced with social and economic challenges now more than ever, which thereby exerts more pressure on their personal lives. The International Labor Organization (ILO) places emphasis on the need to advance the creation of a "decent work" role for every worker (men and women) to perform decent and productive work in conditions of freedom, equity, 
security and human dignity that will aid toward advancing the health and well-being of workers while promoting balance between their work and home life $[3,37,38]$. Based on this submission, the intervention of the QoWL should strive to consider worker participation and involvement in decision making on matters likely to affect them at work.

\section{Conclusions}

This study analyzed the role played by both subjective and behavioral components of QoWL among farm workers in Nigeria as it affects their work-life balance. Based on the study's findings, job characteristics and the associated factors were found to have influenced the QoWL among the respondents based on the seven dimensions mentioned earlier. In addition, QoWL differs across gender and age group. Empirical outcomes from this study demonstrate the importance of having a balance between job satisfaction, wages, hours and working conditions, well-being and the work-life interface, as these key factors can influence worker productivity.

Worker job satisfaction is an important element that can lead to the high productivity and sustainability of the organization. To achieve a level of sustainability and food security in LMICs such as Nigeria, there is a need to improve opportunities for greater stability among farm workers. Furthermore, farm workers' views on workplace safety and wellbeing provisions should be considered in decision making to help understand their occupational expectations. Lastly, large-scale farm operators in Nigeria need to consider putting in place suitable workplace policies that encourage having a good work-life balance among their employees. Similarly, opportunities should be made for farm workers to engage with tailored training initiatives around stress management, work-life balance, workplace safety, health and wellbeing as a means of boosting their confidence and enhancing their productivity. In addition to this, this paper holds the potential to serve as the basis for a framework for assessing QoWL within the farming industry, and allow further research around the impact of job insecurity within the sector.

Supplementary Materials: The following are available online at https:/ /www.mdpi.com/2077-047 2/11/2/103/s1, Table S1: Influence of Quality of Work Life (QoWL) among seasonal farmers workers and workplace commitment.

Author Contributions: Conceptualization, H.M.M. and C.N.; methodology, M.D.; software, M.D.; validation, L.S., P.J.S.D. and F.F.; formal analysis, M.D.; investigation, C.N.; resources, H.M.M.; data curation, C.N.; writing—original draft preparation, H.M.M.; writing—review and editing, C.E.M. and F.F.; visualization, C.E.M.; supervision, H.M.M.; project administration, H.M.M. All authors have read and agreed to the published version of the manuscript.

Funding: This research received no external funding.

Institutional Review Board Statement: The study was conducted in accordance with the Declaration of Helsinki, and the protocol was approved by the Department of Agricultural Technology, Forestry Research Institute of Nigeria. Jos, Ethics Committee. 20 July 2020.

Informed Consent Statement: Informed consent was obtained from all subjects involved in the study.

Data Availability Statement: The data presented in this study are available on request from the corresponding author.

Conflicts of Interest: The authors declare no conflict of interest.

\section{References}

1. Hu, H.; Zhou, H.; Mao, F.; Geng, J.; Zhang, L.; Zhang, X. Influencing Factors and Improvement Strategy to the Quality of Nursing Work Life: A Review. Yangtze Med. 2019, 3, 253-260. [CrossRef]

2. Kong, F.Z.; Zhao, L.; Zhang, X.B.; Tsai, C.H.; Lin, D.D. Farmers' Work-Life Quality and Entrepreneurship Will in China. Front. Psychol. 2019, 10, 787. [CrossRef] [PubMed]

3. Gosetti, G. Sustainable agriculture and quality of working life: Analytical perspectives and confirmation from research. Sustainability 2017, 9, 1749. [CrossRef] 
4. Baksh, K.S.; Ganpat, W.G.; Narine, L.K. Occupational health and safety issues among vegetable farmers in trinidad and the implications for extension. J. Agric. Saf. Health 2015, 21, 159-171. [PubMed]

5. Olowogbon, T.S.; Yoder, A.M.; Fakayode, S.B.; Falola, A.O. Taming Occupational Stress among Farmers in Developing Nations. In Effects of Stress on Human Health; IntechOpen: London, UK, 2019. [CrossRef]

6. Bolarinwa, K.K.; Ayinde, A.F.O.; Adeogun, S.O. Stress coping strategies among agricultural extension agents in Oyo State, Nigeria. J. Agric. Ext. 2016, 20, 163-172. [CrossRef]

7. FAO. Sustainability Assessment of Food and Agriculture Systems Guidelines (Test Version 1.1.). 2012. Available online: http:/ / www.fao.org/3/ap773e/ap773e.pdf (accessed on 28 August 2020).

8. Chan, K.W.; Wyatt, T.A. Quality of Work Life: A study of employees in Shanghai, China. Asia Pac. Bus. Rev. 2007, 13, 501-517. [CrossRef]

9. Moda, H.M.; Minhas, A. Impacts of climate change on outdoor workers and their safety: Some research priorities. Int. J. Environ. Res. Public Health 2019, 16, 3458. [CrossRef]

10. Deary, I.J.; Willock, J.; McGregor, M. Stress in farming. Stress Med. 1997, 13, 131-136. [CrossRef]

11. Hovey, J.D.; Seligman, L.D. The mental health of agricultural workers. In Agricultural Medicine; Springer: New York, NY, USA, 2006.

12. Ramesh, A.S.; Madhavi, C. Occupational stress among farming people. J. Agric. Sci. 2009, 4, 115-125.

13. Easton, S.; Van Laar, D. QoWL (Quality of Working Life): What, how, and why? Psychol. Res. 2013, 3, 596-605. [CrossRef]

14. Fontinha, R.; Van Laar, D.; Easton, S. Quality of working life of academics and researchers in the UK: The roles of contract type, tenure and university ranking. Stud. High. Educ. 2018, 43, 786-806. [CrossRef]

15. Elkington, J. Triple bottom line revolution: Reporting for the third millennium. Aust. CPA 1999, 69, 75-76.

16. Abrey, M.; Smallwood, J.J. The effects of unsatisfactory working conditions on productivity in the construction industry. Procedia Eng. 2014, 85, 3-9. [CrossRef]

17. Denvir, A.; Hillage, J.; Cox, A.; Sinclair, A.; Pearmain, D. Quality of Working Life in the UK; Institute for Employment Studies: Brighton, UK, 2008; pp. 1-65.

18. Aletraris, L. How satisfied are they and why? A study of job satisfaction, job rewards, gender and temporary agency workers in Australia. Hum. Relat. 2010, 63, 1129-1155. [CrossRef]

19. Eaves, S.; Gyi, D.E.; Gibb, A.G. Building healthy construction workers: Their views on health, wellbeing and better workplace design. Appl. Ergon. 2016, 54, 10-18. [CrossRef] [PubMed]

20. Gospel, H. Quality of Working Life: A Review on Changes in Work Organization, Conditions of Employment and Work-Life Arrangements; International Labour Office: Geneva, Switzerland, 2003.

21. Sirgy, M.J.; Efraty, D.; Siegel, P.; Lee, D.J. A new measure of Quality of Work Life (QWL) based on need satisfaction and spillover theories. Soc. Indic. Res. 2001, 55, 241-302. [CrossRef]

22. Huang, H.; Zhang, H.; Xie, Y.; Wang, S.B.; Cui, H.; Li, L.; Shao, H.; Geng, Q. Effect of Balint group training on burnout and Quality of Work Life among intensive care nurses: A randomized controlled trial. Neurol. Psychiatry Brain Res. 2020, 35, 16-21. [CrossRef]

23. Nanjundeswaraswamy, T.S.; Swamy, D.R. Review of Literature on Quality of Work Life. Int. J. Qual. Res. 2013, 7, $201-214$.

24. Requena, F. Social capital, satisfaction and quality of life in the workplace. Soc. Indic. Res. 2003, 61, 331-360. [CrossRef]

25. Van Laar, D.; Edwards, J.A.; Easton, S. The Work-Related Quality of Life scale for healthcare workers. J. Adv. Nurs. 2007, 60, 325-333. [CrossRef]

26. Vagharseyyedin, S.A.; Vanaki, Z.; Mohammadi, E. Quality of Work Life: Experiences of Iranian nurses. Nurs. Health Sci. 2011, 13, 65-75. [CrossRef]

27. Easton, S.; Van Laar, D. User Manual for the Work-Related Quality of Life (WRQoL) Scale: A Measure of Quality of Working Life; University of Portsmouth: Portsmouth, UK, 2018.

28. Tavakol, M.; Dennick, R. Making sense of Cronbach's alpha. Int. J. Med Educ. 2011, 2, 53. [CrossRef] [PubMed]

29. Windon, S.R.; Jepsen, S.D.; Scheer, S.D. Identifying the factors affecting Ohio farmers quality of life. J. Nacaa 2014, 7, 1-7.

30. Herrera, B.; Gerster-Bentaya, M.; Knierim, A. Farm-level factors influencing farmers satisfaction with their work. In Proceedings of the 30th International Conference of Agricultural Economist, Vancouver, BC, Canada, 28 July-2 August 2018.

31. Kang, L.S. Work-family conflict \& Quality of Work Life among veterinary doctors. Indian J. Ind. Relat. 2014, 49, 707-721.

32. Wojewódzka-Wiewiórska, A.; Kłoczko-Gajewska, A.; Sulewski, P. Between the Social and Economic Dimensions of Sustainability in Rural Areas-In Search of Farmers' Quality of Life. Sustainability 2020, 12, 148. [CrossRef]

33. Daghagh Yazd, S.; Wheeler, S.A.; Zuo, A. Key risk factors affecting farmers' mental health: A systematic review. Int. J. Environ. Res. Public Health 2019, 16, 4849. [CrossRef] [PubMed]

34. Sato, M.; Kato, H.; Noguchi, M.; Ono, H.; Kobayashi, K. Gender differences in depressive symptoms and work environment factors among dairy farmers in Japan. Int. J. Environ. Res. Public Health 2020, 17, 2569. [CrossRef] [PubMed]

35. Osborne, A.; Blake, C.; Fullen, B.M.; Meredith, D.; Phelan, J.; McNamara, J.; Cunningham, C. Prevalence of musculoskeletal disorders among farmers: A systematic review. Am. J. Ind. Med. 2012, 55, 143-158. [CrossRef]

36. Mbada, C.E.; Adeyemi, T.L.; Adedoyin, R.A.; Badmus, H.D.; Awotidebe, T.O.; Arije, O.O.; Omotosho, O.S. Prevalence and modes of complementary and alternative medicine use among peasant farmers with musculoskeletal pain in a rural community in South-Western Nigeria. BMC Complement. Altern. Med. 2015, 15, 164. [CrossRef] 
37. Gaviglio, A.; Bertocchi, M.; Marescotti, M.E.; Demartini, E.; Pirani, A. The social pillar of sustainability: A quantitative approach at the farm level. Agric. Food Econ. 2016, 4, 15. [CrossRef]

38. ILO (International Labour Organization). Decent Work: Report of the Director-General, International Labour Conference; ILO: Geneva, Switzerland, 1999; Available online: https:/ / www.ilo.org/public/english/standards/relm/ilc/ilc87/rep-i.htm\#1.\%20The\%20 primary\%20goal (accessed on 7 December 2020). 